\title{
Obituary: G. E. H. REUTER
}

It was with great sadness that his many friends learned of the death on 20 April 1992 of G. E. H. (Harry) Reuter, at the age of 70.

The space of this obituary for the Applied Probability Trust does not allow for more than the briefest account of Harry's life and work. The reader is referred to forthcoming obituaries for a fuller account, to David Kendall's appreciation in the Reuter Festschrift (Kendall (1986)), and to Krengel's in the DMV Jubilee Volume (Krengel (1990), §6) (see also the obituary notices in The Times of 9 and 18 May and the LMS Newsletter 195, June 1992).

Gerd Edzard Harry Reuter (known as Harry from the cradle to the grave) was born in Berlin on 21 November 1921, the son of Ernst and Charlotte Reuter. Ernst Reuter (1889-1953), a member of the Reichstag for the SPD (Social Democrats) from 1932, was subjected to political persecution on the accession to power of the Nazis in 1933, and the Reuter family became refugees. Ernst Reuter is best remembered now for his role as Burgomeister of West Berlin during the postwar confrontation with Stalin and the Berlin Air Lift of 1948-49; he is commemorated in the name of the Ernst Reuter Platz, the postal address of the Technical University of (formerly West) Berlin.

Harry Reuter came to England (speaking little English) in 1935, and was raised in the household of the distinguished Cambridge analyst Dr J. C. (Charles) Burkill FRS. Here mathematics was, in Harry's words, 'in the air' (Charles and Greta Burkill raised not one refugee mathematician but two: their second adopted son is Dr Harry Burkill, an analyst at the University of Sheffied). Harry Reuter thus became a member of the sizeable and distinguished group of British mathematicians who began life here as German refugees; Harry's case was unusual in that he was not Jewish, but came for political reasons.

Like many other mathematicians of his generation, Harry had his education interrupted by war service. He had been educated at the Leys School, and gone up to Trinity College, Cambridge, taking Part II of the Mathematical Tripos in 1941. Having by then acquired British nationality, he served as a Scientific Officer with the Admiralty. The mathematical community will remember Harry's war service from his role (with John Todd) in securing the Mathematisches Forschungsinstitut Oberwolfach in 1945 for the postwar mathematical community (Gericke (1984)).

Returning to Trinity as a research student, Harry continued his studies in analysis: classical (from Littlewood and Cartwright) and functional (from Smithies). In 1946, without finishing a doctorate, Harry was recruited to Manchester by Max Newman. The Department of Mathematics at Manchester in the early postwar period had great success in building a nucleus of very high-calibre staff (for instance, Turing was recruited in 


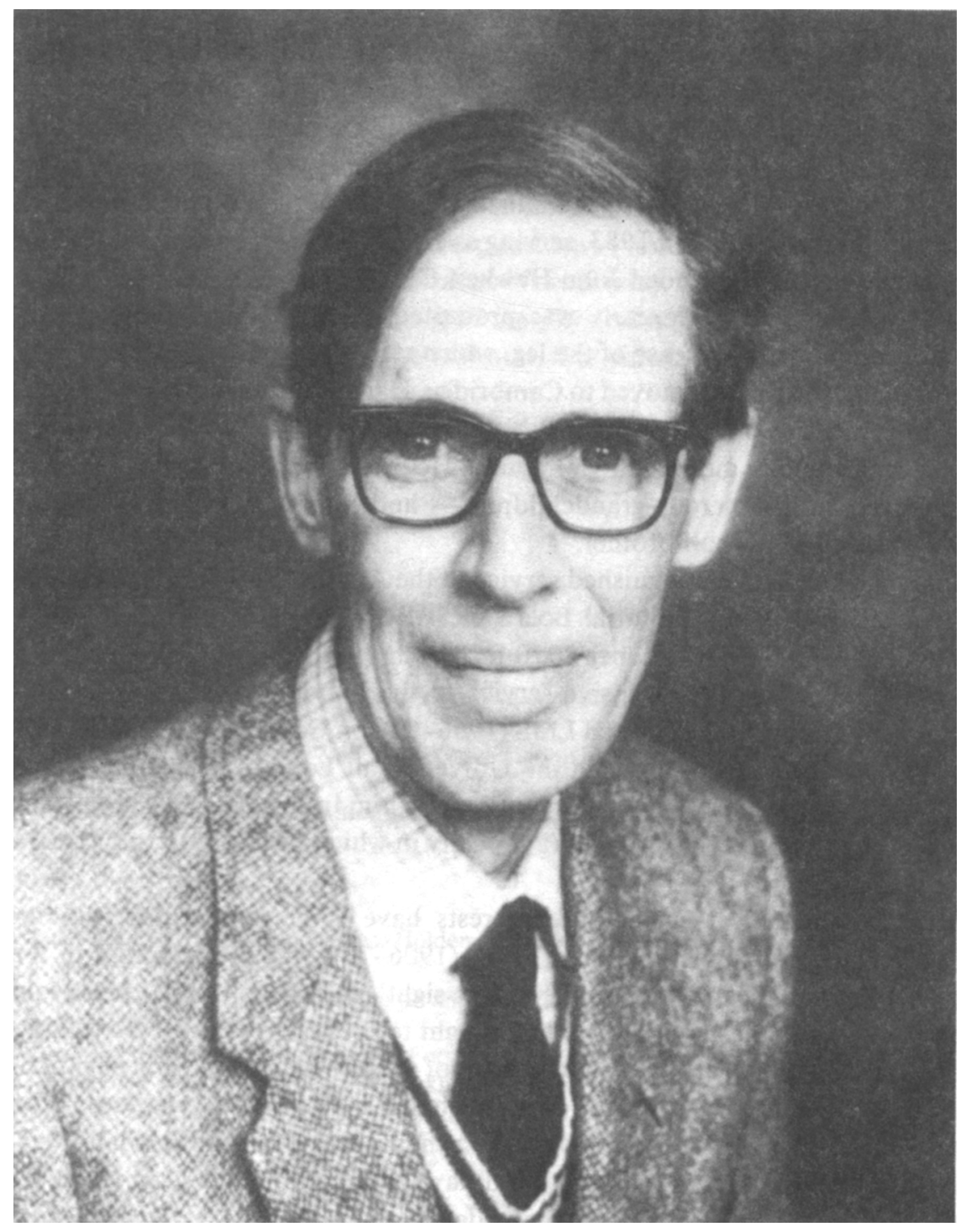

G. E. H. REUTER (1921-1992) 
1948); many felt that Manchester in its 'great period' matched - or surpassed Cambridge. It was here (in correspondence, following a suggestion by Gerald Friedlander) that Harry's analytical skill (with integral equations) was brought to bear on a highly topical problem in physics, resulting in his famous work of 1948 with Ernst Sondheimer on the anomalous skin effect in metals. Here also (with Walter Ledermann and David Kendall) Harry began the work on Markov chains for which he is best known.

In 1959 Harry accepted a chair in Pure Mathematics at Durham. He was by this time a full-blooded probabilist, continuing to work on Markov chains and processes; his research students from this period include David Williams, Ron Doney and Chris Ridler-Rowe.

In 1965 Harry took a chair in Pure Mathematics at Imperial College, London. He held this post till his retirement in 1983, serving as Head of Department from 1979-83. His research students here included John Hawkes, David Emery and Alan Cornish.

Harry's decision to retire early was prompted partly by his declining health (he suffered from a wasting disease of the leg, which steadily decreased his mobility). After his retirement, the Reuters moved to Cambridge. Harry continued to be mathematically active for some time (he was proud that his last paper, with Dame Mary Cartwright, had authors' ages totalling more than 150 years!). He is survived by his widow Eileen, their four children and numerous grandchildren - and his foster father, Charles Burkill (b. 1900) as well as his half-brother.

Harry gave long and distinguished service to the Applied Probability Trust. He was a founding member of the Editorial Board of JAP in 1964, serving till 1988 (as LMS Trustee of the APT from October 1970 to March 1983, and as Co-ordinating Editor from 1983). He also gave extensive service to the London Mathematical Society, as Secretary and Editor to the Journal LMS (1966-69), on Council, and as Vice-President. With James Taylor, Harry founded the University of London Probability Seminar in 1965; I was fortunate to serve as co-organiser with him from 1976-83. He was a founder Trustee of the Rollo Davidson Trust (a capacity in which I was proud to succeed him in 1989).

Harry's mathematical career and interests have some similarities with those of another refugee probabilist, William Feller (1906-70), whom Harry met in the USA during his Durham years ('it was love at first sight', in Feller's words to Kendall). Like Feller, Harry was a master analyst, who brought to probability theory the techniques of classical and functional analysis, in particular of differential and integral equations. Like Feller, Harry was most attracted by Markov chains and processes, and these proved his most enduring interest. The Reuter papers on chain theory, like the Kendall-Reuter and Ledermann-Reuter ones, are classics, and have profoundly influenced the subsequent development of the subject. Some of these ideas have entered the textbook literature (see e.g. Freedman (1971), (1972)), though perhaps the best indication of the invigorating effect on chain theory of Reuter's influence is seen in the early works of David Williams (his student, with Kendall) on $Q$-matrices and the construction problem for Markov chains. This last is still topical; see for instance the recent work of the Chinese school, reviewed by Pollett (1992). Harry had far more ideas than he published. Various unpublished gems of Reuterian analysis have influenced the work of others (Kendall 
(1974), 368, 409-10 on bird navigation, Rogers and Williams (1987), IV. 39 on drifting Brownian motion, ...). Harry even wrote a book on differential equations in his Manchester days, although Newman growled at him, 'you won't get a chair like that, my boy'; an elementary version was published in the Library of Mathematics series (see [34] in the supplementary publications list below).

But it is for his personal qualities that those fortunate enough to have known Harry will best remember him. He had a first-rate mind; nothing that Harry did - research, teaching, administration - was hurried or skimped; he was a perfectionist, without being fussy. He had a delightful sense of humour, which he would deploy with a straight face and in his own inimitable tones (he spoke with no trace of his native German but utterly distinctively - in a Harry Reuter accent, as it were). He had wisdom and humanity, a light touch, and a wry and sceptical way ('les choses sont contre nous', he would say when I grumbled about the burdens of academia). And - supported always by his devoted wife Eileen - he bore his growing physical afflictions with a courage and dignity which impressed everyone who saw him. We will all miss him.

Royal Holloway and Bedford New College, London

N. H. BINGHAM

June 1992

\section{Publications of Harry Reuter, Supplementary list}

The list in Kendall (1986) is completed as follows.

[32] On Kendall's conjecture concerning $\mathrm{O}^{+}$equivalence of Markov transition functions. J. London Math. Soc. (2) 35 (1987), 377-384.

[33] On periodic solutions of Van der Pol's equation with sinusoidal forcing term and large parameter. (With M. L. Cartwright) J. London Math. Soc. (2) 36 (1987), 102-114.

[34] Elementary Differential Equations and Operators (1958). Routledge and Kegan Paul, London.

\section{References}

Freedman, D. (1971) Markov chains. Holden Day, San Francisco (reprinted by Springer-Verlag, 1983).

Freedman, D. (1972) Approximating Countable Markov Chains. Holden Day, San Francisco (reprinted by Springer-Verlag, 1983).

GerICKE, H. (1984) Das Mathematische Forschungsinstitut Oberwolfach. In: Perspectives in Mathematics. Anniversary of Oberwolfach, 1984. Birkhäuser, Basel.

Kendall, D. G. (1974) Pole-seeking Brownian motion (with Discussion). J. R. Statist. Soc. B 36, 365-417.

Kendall, D. G. (1986) (ed., with J. F. C. Kingman and D. Williams) Analytic and Geometric Stochastics: Papers in Honour of G. E. H. Reuter. Special Supplement, Adv. Appl. Prob. 18.

KRENGEL, U. (1990) Wahrscheinlichkeitstheorie. In: Ein Jahrhundert Mathematik 1890-1990. Festschrift zur Jubiläum der DMV, ed. G. Fischer et al., pp. 457-489, Vieweg, Braunschweig/Wiesbaden.

Pollett, P. K. (1992) Review of The Constructive Theory of Denumerable Markov Processes, by Xiang-qun Yang. Ann. Prob. 20, 549-552.

Rogers, L. C. G. AND Williams, D. (1987) Diffusions, Markov Processes and Martingales. Volume 2: Itô Calculus. Wiley, New York. 